\title{
Pre-exposures of Aerosolized Polyvalent Bacterial Lysates Protect Against Bleomycin-Induced Pulmonary Fibrosis in Mice - An Exploratory Study
}

\section{Xiaoling Zhu}

Wuhan Xiehe Hospital: Wuhan Union Hospital

\section{Shan Yuan}

Wuhan Xiehe Hospital: Wuhan Union Hospital

\section{Xiaofang Zheng}

Wuhan Xiehe Hospital: Wuhan Union Hospital

Xiaorong Wang

Wuhan Xiehe Hospital: Wuhan Union Hospital

Jinnong Zhang ( $\nabla$ jnzhangxh@hust.edu.cn )

Wuhan Union Hospital https://orcid.org/0000-0002-8331-3584

\section{Research Article}

Keywords: Polyvalent bacterial lysates, Bleomycin-induced pulmonary fibrosis, Immunostimulation

Posted Date: October 25th, 2021

DOI: https://doi.org/10.21203/rs.3.rs-893411/v1

License: (c) (1) This work is licensed under a Creative Commons Attribution 4.0 International License. Read Full License 


\section{Abstract}

\section{Rationale}

Idiopathic pulmonary fibrosis (IPF) is a chronic fibrosing interstitial pneumonia of unknown cause, no therapeutic modalities could reverse or stop its ever deteriorating course. It has been found that stimulation of lung innate immunity using bacterial lysates protected against lethal pulmonary infection, we speculate it may also protect against the development of pulmonary fibrosis.

\section{Methods}

C57BL/6 mice were exposed to an aerosolized mixture of polyvalent bacterial lysates (PVBLs) or phosphate-buffered saline (PBS, as control) three times on separate day, thereafter the lungs were intratracheally infused of Bleomycin (BLM). Pulmonary morphology, Ashcroft's scale of pulmonary fibrosis and pro-inflammatory cytokines such as interferon (IFN)- $y$ and interleukin (IL)-4 were evaluated 14 days later.

\section{Results}

Exposures of PVBLs did not induce any discernible structural abnormalities in the lung, while the ratio of IFN- $y /$ IL-4 was increased $(P<0.05)$; BLM-induced pulmonary fibrosis was associated with an overwhelming down-regulation of IFN-y and IL-4 $(P<0.01)$; In comparison with the controls, preexposures of the PVBLs protected against BLM-induced pulmonary fibrosis, that was demonstrated by a greater reduction of Ashcroft's fibrotic score [median (95\% Cl): $3.94(3.33-4.56)$ vs. $3.04(2.55-3.52), P<$ 0.05 ] and a greater decrease of hydroxyproline $(0.93 \pm 0.16 \mathrm{vs} .0 .64 \pm 0.18, \mathrm{~g} / \mathrm{mg}, P<0.01)$ as well. Though the PBVLs pre-exposures did not restore the BLM-induced down-regulation of IL-4 and IFN- $\gamma$, the ratio of IFN- $y / \mathrm{IL}-4$ maintained greater than that in the controls $(2.25 \pm 0.70$ vs. $0.78 \pm 0.33, P<0.01)$.

\section{Conclusions}

BLM-induced murine pulmonary fibrosis is associated with an overwhelming down-regulation of IFN-Y and IL-4. Pre-exposures of the aerosolized PVBLs protect against the BLM-induced pulmonary fibrosis.

\section{Introduction}

Idiopathic pulmonary fibrosis (IPF) is a unique form of chronic, progressive, fibrosing interstitial pneumonia of unknown cause [1], it responds poorly to any anti-inflammatory therapy [2-6]. Knowledge in recent studies implied that the development of pulmonary fibrosis is likely relevant to an insufficient innate immunity in the lung $[7,8]$, anti-inflammatory therapies had no effect or even caused worse outcome $[4,9]$. Conversely, we speculate that the IPF patients might benefit from an immuneenhancement treatment rather than an immunosuppressive therapy. 
Current recommendation for IPF management focuses on extracellular matrix (ECM) inhibition, representative agents include Nintedanib (an intracellular inhibitor of tyrosine kinases) and pirfenidone (with unknown mechanism) [10], but the benefits are far from satisfactory, which are only limited to a slight deceleration of the ever declining lung function in IPF patients [11-13]. For elderly patients or the patients with progressive fibrotic interstitial lung diseases [14, 15], adherence to Nintedanib or pirfenidone treatment is troubled by poor toleration. Therefore, therapeutic modalities for cure or optimal alleviation of symptom should be continuously searched for.

Bacterial lysates positively modulate the body's innate immunity (so called immune-stimulating enhancement) and nonspecifically enhance pulmonary resistance against infections of a variety of lethal microbials [16-18]. In present study, we explored whether the immune-stimulating enhancement by repeat exposures to bacterial lysates leads to protection against Bleomycin-induced pulmonary fibrosis.

\section{Materials And Methods}

\section{Animals}

Specific pathogen-free (SPF) female C57BL/ 6 mice, 6-week old with body weight of $18.64 \pm 0.22 \mathrm{~g}$, were purchased from Vital River Laboratory Animal Technology Co., Ltd., Beijing, China. The animals were bred in a SPF room (ambient temperature $22-26^{\circ} \mathrm{C}$, humidity $60-70 \%$ ) and scrutinized for fitness upon arrival for three days, then randomized into different study groups and used within 2 weeks. The laboratory animal management rules of Tongji Medical College of Huazhong University of Science and Technology were strictly adhered to.

\section{Polyvalent bacterial lysate and other laboratory materials}

A mixture of polyvalent bacterial lysates (PVBLs) was used as the immunostimulant (Broncho-Vaxom ${ }^{\mathrm{TM}}$, batch No. S20150042, OM Pharma, Switzerland), it contains extracts derived from 8 bacterial species (Staphylococcus aureus, Streptococcus viridans, Streptococcus pyogenes, Diplococcus pneumoniae, Klebsiella pneumoniae, Klebsiella ozaenae, Neisseria catarrhalis, and Haemophilus influenza) [16]. Injection formulation of Bleomycin hydrochloride (BLM, batch No. H20055883) was purchased from HiSun Pharmaceutical CO., LTD, Zhejiang, China. A self-made transparent polyethylene exposure chamber $(35 \mathrm{~cm} \times 25 \mathrm{~cm} \times 20 \mathrm{~cm})$ with a connection to the outlet of a nebulizer (type NE-C900, OMRON) was set for the aerosolized PVBLs exposure.

\section{Animal models}

Firstly, we investigated the impact of aerosolized PVBLs on the animals' general condition and lung morphology. The mice were randomized into 2 groups and put in the exposure chamber alternatively during an episode of the aerosol exposure, when the animals were either exposed to the aerosol of 10.5 $\mathrm{mg}$ PVBLs dissolved in $6 \mathrm{ml}$ sterile PBS solution or to the aerosol of $6 \mathrm{ml}$ sterile PBS solution (shamed exposure as control) at the $1 \mathrm{st}$, 4th and 7th day of the experimental course. At the 8 th day, we anesthetized the mouse by intraperitoneal injection of $50 \mathrm{mg} / \mathrm{kg} \cdot$ body weight (bw) sodium pentobarbital 
solution $1 \mathrm{ml}$ and fixed the animal on a small animal surgery board when the anesthesia took into effect (lack of withdrawal reflex upon pinching a toe). We exposed the trachea through a standard aseptic surgery and infused $0.5 \mathrm{ml}$ of sterile normal saline (NS) solution into the trachea during inspiration. To ensure a homogenous distribution, we blew $0.5 \mathrm{ml}$ air into the trachea twice and then rotated the animal body for 2 minutes. After closing and sterilizing the wound, the animal was cared for on a warm pad $\left(36^{\circ} \mathrm{C}\right)$ until fully recovery from anesthesia.

In the second step, we explored the effect of the multiple pre-exposures of the PVBLs on BLM-induced pulmonary fibrosis. Similarly, at each episode of the PVBLs exposure, the mice were put into the chamber and exposed to the aerosol of $10.5 \mathrm{mg}$ PVBLs dissolved in $6 \mathrm{ml}$ sterile PBS solution at the $1 \mathrm{st}$, 4th and 7 th day of the experimental course. At the 8 th day, the animal was intra-tracheally infused $4 \mathrm{mg} / \mathrm{kg} \cdot \mathrm{bw}$ BLM dissolved in $0.5 \mathrm{ml}$ sterile NS, followed by blowing $0.5 \mathrm{ml}$ air into the lung twice and 2-minute body rotation. The care for the animal after that was the same as described above.

\section{Pulmonary morphology and morphometry}

On the 22nd day of the experiment, i.e., 14 days later after intra-tracheal BLM infusion, the mice were euthanized by intraperitoneal injection of sodium pentobarbital $100 \mathrm{mg} / \mathrm{kg} \cdot \mathrm{bw}$ and exsanguinated by severing the abdominal aorta immediately after death. We intratracheally intubated the animal, removed its right lung en bloc upon ligation of the right main bronchus, infused the left lung via the tracheal catheter with $4 \%$ paraformaldehyde (PFA) solution at a constant hydrostatic pressure of $20 \mathrm{~cm}$ for at least 20 minutes (until the pleural surface became smooth), then we fully immersed the left lung in PFA solution for at least 4 hours before further histological processing. The right lung was stored in $-80^{\circ} \mathrm{C}$ for further biochemistry measurement. The PFA fixed lungs were paraffin embedded and sagittal sections of mid-part of the lung sample with $4 \mu \mathrm{m}$ thickness were deparaffinized and stained with hematoxylin and eosin.

Morphometric evaluation was referred to a modified Ashcroft's scale [19]. Briefly, ten non-overlapping pulmonary microscopic fields under a 10-fold magnification were randomly selected for each slice of a specimen. The assignment of grades from 0 to 8 was based on the extent of fibrosis in alveolar septa and lung structure. To ensure the objectivity, three experts of pulmonary fibrosis pathology who blinded to the study design did the scoring. The average of the three scores was taken as the final score.

\section{Determination of Hydroxyproline in lung tissue}

The hydroxyproline content in lung tissue was measured using a Hydroxyproline Assay Kit (batch No. A030-2, JianCheng Bioengineering Institute, Nanjing, China).

\section{Determination of IL-4 and IFN-y in bronchoalveolar lavage fluid}

For determination of IL-4 and IFN- $y$ in bronchoalveolar lavage fluid (BALF), the mice were also euthanized by intraperitoneal injection of sodium pentobarbital $100 \mathrm{mg} / \mathrm{kg} \cdot \mathrm{bw}$ at the 22th day of the experiment. The 
procedure for collecting BALF was as that reported preciously [20]. IL-4 and IFN-y in the BALF was measured using an ELISA kit for IL-4 and IFN-ץ (batch No. E-EL-M0727, Elabscience Biotechnology Co.,Ltd., Wuhan, China) according to the manufacturer's instruction.

\section{Statistics}

Statistical analyses were performed using SPSS 19.0 for Windows (IBM, USA) by a statistician who blinded to the study design. Test of normal distribution was by Kolmogorov-Smirnov method, the data approximated as normal distribution was expressed as mean $\pm \mathrm{Sd}$, the parametric statistics such as ANOVA and post hoc Dunnett's comparisons were applied where appropriate. Results of Ashcroft's scale were presented as median and $95 \%$ confidence interval $(\mathrm{Cl})$, the non-parametric statistics such as Kruskal-Wallis ANOVA \& Median test and Mann-Whitney $U$ test were used for inter-group comparisons of the Ashcroft's scores. $P<0.05$ was defined as statistical significant.

\section{Results}

\section{Animals' general condition}

The animals seemed to be mildly irritated by the exposures, no matter being exposed to PVBLs or PBS, manifested by frequent ear and nose scratching, hair grooming and a slight breath gasping. These manifestations tapered off after cessation of the exposure, usually 10 minutes later. No death happened during or after the exposures. The body-weight difference between the animals with BLM infusion and the controls reached statistical significance 7 days later after intra-tracheal infusion, and the difference maintained until the day of sacrifice $(P<0.05$, Fig. 1$)$.

\section{Pulmonary morphology, morphometry and hydroxyproline}

Exposure to PVBLs or PBS then intra-tracheal infusion of NS did not induce any overt morphological abnormalities in pulmonary structural and alveolar septa, the modified Ashcroft's scores in the two group were approximate equal (1.36 vs. 1.27 , Fig. $2 a$ and $b$, Table $1, P>0.05$ ). While, the intra-tracheal infusion of BLM caused a diffuse lung damage and a large scale of alveolar septa thickening (Fig. 2c). Repeat PVBLs pre-exposures protected against the development of pulmonary fibrosis compared to the animals with the controls, the former demonstrated less pulmonary damage, smaller modified Ashcroft's score and reduced hydroxyproline content in the lung homogenate (Fig. $2 \mathrm{~d}$ and Table $1, P<0.01$ ). 
Table 1

Pulmonary modified Ashcroft's scores and contents of hydroxyproline, IL-4 and IFN- in mice with repeat PVBLs exposures and then intra-tracheal bleomycin instillation

\begin{tabular}{|c|c|c|c|c|c|}
\hline \multicolumn{6}{|l|}{$Y$} \\
\hline \multirow[t]{2}{*}{ Groups } & \multirow[t]{2}{*}{ Ashcrof's score $\S$} & Hydroxyproline & IFN-y & IL-4 & IFN-y / IL-4 \\
\hline & & $(\mu \mathrm{g} / \mathrm{mg})$ & $(\mu \mathrm{g} / \mathrm{L})$ & $(\mu \mathrm{g} / \mathrm{L})$ & \\
\hline PBS & $\begin{array}{l}1.36(0.88- \\
1.84)^{*}\end{array}$ & $0.76 \pm 0.20^{*}$ & $\begin{array}{l}209.96 \pm \\
41.24 \star \star\end{array}$ & $\begin{array}{l}133.06 \pm \\
33.67 \star \star\end{array}$ & $1.63 \pm 0.42$ \\
\hline PVBLs & $\begin{array}{l}1.27(0.74- \\
1.81)^{\star}\end{array}$ & $0.78 \pm 0.11^{*}$ & $\begin{array}{l}168.12 \pm \\
8.17^{\star \star}\end{array}$ & $60.45 \pm 17.83$ & $\begin{array}{l}3.06 \pm \\
1.22^{\star \star}\end{array}$ \\
\hline PBS-BLM & $\begin{array}{l}3.94(3.33- \\
4.56)\end{array}$ & $0.93 \pm 0.16$ & $35.28 \pm 12.73$ & $46.97 \pm 10.56$ & $0.78 \pm 0.33$ \\
\hline $\begin{array}{l}\text { PVBLs- } \\
\text { BLM }\end{array}$ & $\begin{array}{l}3.04(2.55- \\
3.52)^{\star}\end{array}$ & $0.64 \pm 0.18^{\star \star}$ & $63.67 \pm 21.38$ & $28.88 \pm 5.50$ & $\begin{array}{l}2.25 \pm \\
0.70^{\star \star}\end{array}$ \\
\hline \multicolumn{6}{|c|}{ §Data are presented as mean $\pm \mathrm{Sd}$ or median and $95 \% \mathrm{Cl}$. } \\
\hline \multicolumn{6}{|c|}{$\begin{array}{l}{ }^{\star} P<0.05,{ }^{* \star} P<0.01 \text { as compared to the correspondent variables in group PBS-BLM, in which the } \\
\text { animals exposed to PBS before BLM intra-tracheal instillation, whereas in group PVBLs-BLM, the } \\
\text { animals exposed to PVBLs before BLM instillation. }\end{array}$} \\
\hline
\end{tabular}

\section{Cytokines}

In comparison with PBS exposure, the PVBLs exposures decreased the IL-4 expression in the BALF, thereafter, resulted in a greater ratio of IFN- $\gamma / \mathrm{IL}-4$ than that in the controls $(3.06 \pm 1.22$ vs. $1.63 \pm 0.42$, Table 1, $P<0.01)$. Intra-tracheal infusion of BLM caused an overwhelming down-regulation of IFN- $y$ and IL-4 in the BALF (Table 1, $P<0.01$ ), no matter the pre-exposures were the PVBLs or PBS. However, the greater ratio of IFN- $\gamma / \mathrm{IL}-4$ in the mice with the PVBLs pre-exposures was maintained ( $2.25 \pm 0.70 \mathrm{vs} .0 .78$ \pm 0.33 in the controls, Table $1, P<0.01$ ).

\section{Discussion}

Repeat exposures of the PVBLs aerosol seem to be safe to the mice. Though the animals were mildly irritated by the exposures, no big behavior difference were noted between the two groups, hence, we assume that the animals might just be slightly offended by the moisture of the aerosols rather than the content in the aerosols. The exposures of the PVBLs likely initiated an immune response with Th1 predilection as implied by a greater ratio of IFN- $\gamma /$ IL-4 in the mice with the PVBLs exposures than that in the controls (Table 1), similar to that in previous studies using oral exposure of bacterial extracts $[21,22]$.

The impact of intra-tracheal infusion of BLM on the mice is huge and negative, it not only stagnated the gain of body weight but also overwhelmingly down-regulated IL-4 and IFN-y expressions in the lung (with 
an even greater decline in IFN-y). This phenomenon is in harmony with our postulation that the pulmonary fibrosis is a disease of receded innate immunity with a Th2 skewness rather than a disease of exaggerated inflammation [3]. Some other evidences also support this speculation, which could be dug out in a recent review by Heukels and colleagues [23].

The intra-tracheal infusion of BLM was done 24 hours later after the PVBLs exposures, when the pulmonary defense was strong enough against lethal microbial infections as shown in Evens' study [17]. In this study we demonstrate that the PVBLs exposures also protect against BLM induced lung fibrosis (mirrored by less morphological severity of fibrosis, degraded Ashcroft's scale and lower hydroxyproline content compared to the mice of control), implying that the effect of immune-stimulating enhancement of PVBLs acts non-specifically, which not only protects the pulmonary mucosa against pathogenic microbials infection but also against some fibrosing insults, like BLM.

Since this is a preliminary and exploratory study, we only detected the expressions of IFN- $y$ and IL-4 for a briefly elucidation of the mechanism of PVBLs. The maintenance of a greater ratio of IFN- $\mathrm{Y} / \mathrm{IL}-4$ even after BLM infusion in the lung with PVBLs pre-exposure infers that the maintenance of a Th1 polarized immune response, though being suppressed very much, is still important in protecting against the development of BLM-induced pulmonary fibrosis.

Taken above together, we conclude that the BLM-induced pulmonary fibrosis is associated with a significant suppression of the innate immunity. Repeat PVBLs pre-exposures not only protect against lethal microbial infections but also against BLM-induced pulmonary fibrosis. Repeat PVBLs exposures possibly serve as a cue for strengthening the innate immunity with a feature of Th1 skewness.

Limitation of this study: 1 . the animal model is a form of an acute pulmonary fibrosis rather than a chronic one, therefore, the result of this study should not be directly applied to human IPF; 2 . the behavior inspection and the morphological study are not the efficient ways to exclude the functional side effects delivered by airway PVBLs exposures; 3 . ratio of IFN- $y$ and IL-4 is far from enough to elucidate the mechanism that the PVBLs pre-exposures alleviate BLM-induced pulmonary fibrosis. Other representative biomarkers of innate immunity and adaptive immunity should be investigated in future.

\section{Declarations}

Acknowledgments. The authors thank Xiaofei Hu and Wenjing Wang for their technical assistance.

Funding information. This work was funded by the National Natural Science Foundation of China. No. 81370147.

Conflicts of interest. The authors declare that they have no conflict of interest.

Availability of data and material. The data and material used and/or analyzed during the current study are available from the corresponding author on reasonable request. 
Authors' contributions. Xiaoling Zhu, Shan Yuan and Xiaofang Zheng performed the animal study and analyzed the data. Xiaorong Wang involved in the morphometric study and data analysis. Xiaoling Zhu also involved in the study design and drafted the manuscript. Jinnong Zhang initiated, designed and supervised the study, he also involved in revision of the manuscript. All authors have read and approved the final manuscript.

Ethics approval. Ethical approval was obtained from the Ethics Committee of Tongji Medical College, Huazhong University of Science and Technology.

Code availability. Not applicable.

Consent to participate. Not applicable.

Consent for publication. Not applicable.

\section{References}

1. Raghu G, Remy-Jardin M, Myers JL, Richeldi L, Ryerson CJ, Lederer DJ, Behr J, Cottin V, Danoff SK, Morell F, Flaherty KR, Wells A, Martinez FJ, Azuma A, Bice TJ, Bouros D, Brown KK, Collard HR, Duggal A, Galvin L, Inoue Y, Jenkins RG, Johkoh T, Kazerooni EA, Kitaichi M, Knight SL, Mansour G, Nicholson AG, Pipavath SNJ, Buendía-Roldán I, Selman M, Travis WD, Walsh S, and Wilson KC. 2018. Diagnosis of idiopathic pulmonary fibrosis. An official ats/ers/jrs/alat clinical practice guideline. American journal of respiratory and critical care medicine 198 (5): 44-68.

2. Guler SA, Clarenbach C, Brutsche M, Hostettler K, Brill AK, Schertel A, Geiser TK, and Funke-Chambour M. 2021. Azithromycin for the treatment of chronic cough in idiopathic pulmonary fibrosis: $A$ randomized controlled cross-over trial. Ann Am Thorac Soc. https://doi.org/10.1513/AnnalsATS.202103-2660C

3. Raghu G. 2017. Idiopathic pulmonary fibrosis: Lessons from clinical trials over the past 25 years. The European respiratory journal;50 (4).

4. Raghu G, Anstrom KJ, King TE, Jr., Lasky JA, and Martinez FJ. 2012. Prednisone, azathioprine, and nacetylcysteine for pulmonary fibrosis. The New England journal of medicine 366 (21): 1968-1977.

5. Lynch JP, 3rd, White E, and Flaherty K. 2001. Corticosteroids in idiopathic pulmonary fibrosis. Current opinion in pulmonary medicine 7 (5): 298-308.

6. Flaherty KR, Toews GB, Lynch JP, 3rd, Kazerooni EA, Gross BH, Strawderman RL, Hariharan K, Flint A, and Martinez FJ. 2001. Steroids in idiopathic pulmonary fibrosis: A prospective assessment of adverse reactions, response to therapy, and survival. Am J Med 110 (4): 278-282.

7. Papanikolaou IC, Boki KA, Giamarellos-Bourboulis EJ, Kotsaki A, Kagouridis K, Karagiannidis N, and Polychronopoulos VS. 2015. Innate immunity alterations in idiopathic interstitial pneumonias and rheumatoid arthritis-associated interstitial lung diseases. Immunology letters 163(2): 179-186. 
8. Li S, Hu X, Wang Z, Wu M, and Zhang JN. 2015. Different profiles of notch signaling in cigarette smoke-induced pulmonary emphysema and bleomycin-induced pulmonary fibrosis. Inflammation research : official journal of the European Histamine Research Society 64 (5): 363-371.

9. Martinez FJ, de Andrade JA, Anstrom KJ, King TE, Jr., and Raghu G. 2014. Randomized trial of acetylcysteine in idiopathic pulmonary fibrosis. The New England journal of medicine 370 (22): 2093-2101.

10. Wells AU, Kokosi M, and Karagiannis K. 2014. Treatment strategies for idiopathic interstitial pneumonias. Current opinion in pulmonary medicine 20 (5): 442-448.

11. Richeldi L, du Bois RM, Raghu G, Azuma A, Brown KK, Costabel U, Cottin V, Flaherty KR, Hansell DM, Inoue Y, Kim DS, Kolb M, Nicholson AG, Noble PW, Selman M, Taniguchi H, Brun M, Le Maulf F, Girard M, Stowasser S, Schlenker-Herceg R, Disse B, and Collard HR. 2014. Efficacy and safety of nintedanib in idiopathic pulmonary fibrosis. The New England journal of medicine 370 (22): 2071-2082.

12. King TE, Jr., Bradford WZ, Castro-Bernardini S, Fagan EA, Glaspole I, Glassberg MK, Gorina E, Hopkins PM, Kardatzke D, Lancaster L, Lederer DJ, Nathan SD, Pereira CA, Sahn SA, Sussman R, Swigris JJ, and Noble PW. 2014. A phase 3 trial of pirfenidone in patients with idiopathic pulmonary fibrosis. The New England journal of medicine 370 (22): 2083-2092.

13. Karimi-Shah BA, and Chowdhury BA. 2015. Forced vital capacity in idiopathic pulmonary fibrosis-FDA review of pirfenidone and nintedanib. The New England journal of medicine 372 (13): 11891191.

14. Richeldi L, Cottin V, du Bois RM, Selman M, Kimura T, Bailes Z, Schlenker-Herceg R, Stowasser S, and Brown KK. 2016. Nintedanib in patients with idiopathic pulmonary fibrosis: Combined evidence from the tomorrow and inpulsis $(\circledR)$ trials. Respiratory medicine 113: 74-79.

15. Behr J, Prasse A, Kreuter M, Johow J, Rabe KF, Bonella F, Bonnet R, Grohe C, Held M, Wilkens H, Hammerl P, Koschel D, Blaas S, Wirtz H, Ficker JH, Neumeister W, Schönfeld N, Claussen M, Kneidinger N, Frankenberger M, Hummler S, Kahn N, Tello S, Freise J, Welte T, Neuser P, and Günther A. 2021. Pirfenidone in patients with progressive fibrotic interstitial lung diseases other than idiopathic pulmonary fibrosis (relief): A double-blind, randomised, placebo-controlled, phase $2 b$ trial. Lancet Respir Med 9 (5): 476-486.

16. Kearney SC, Dziekiewicz M, and Feleszko W. 2015. Immunoregulatory and immunostimulatory responses of bacterial lysates in respiratory infections and asthma. Ann Allergy Asthma Immunol 114 (5): 364-369.

17. Evans SE, Scott BL, Clement CG, Larson DT, Kontoyiannis D, Lewis RE, Lasala PR, Pawlik J, Peterson JW, Chopra AK, Klimpel G, Bowden G, Höök M, Xu Y, Tuvim MJ, and Dickey BF. 2010. Stimulated innate resistance of lung epithelium protects mice broadly against bacteria and fungi. American journal of respiratory cell and molecular biology 42 (1): 40-50.

18. Clement CG, Evans SE, Evans CM, Hawke D, Kobayashi R, Reynolds PR, Moghaddam SJ, Scott BL, Melicoff E, Adachi R, Dickey BF, and Tuvim MJ. 2008. Stimulation of lung innate immunity protects 
against lethal pneumococcal pneumonia in mice. American journal of respiratory and critical care medicine 177 (12): 1322-1330.

19. Hübner RH, Gitter W, El Mokhtari NE, Mathiak M, Both M, Bolte H, Freitag-Wolf S, and Bewig B. 2008. Standardized quantification of pulmonary fibrosis in histological samples. Biotechniques 44 (4): 507-511, 514-507.

20. Daubeuf F, and Frossard N. 2012. Performing bronchoalveolar lavage in the mouse. Current protocols in mouse biology 2 (2): 167-175.

21. Han L, Zheng CP, Sun YQ, Xu G, Wen W, and Fu QL. 2014. A bacterial extract of om-85 bronchovaxom prevents allergic rhinitis in mice. American journal of rhinology \& allergy 28 (2): 110-116.

22. Bowman LM, and Holt PG. 2001. Selective enhancement of systemic th 1 immunity in immunologically immature rats with an orally administered bacterial extract. Infection and immunity 69 (6): 3719-3727.

23. Heukels P, Moor CC, von der Thüsen JH, Wijsenbeek MS, and Kool M. 2019. Inflammation and immunity in ipf pathogenesis and treatment. Respiratory medicine 147: 79-91.

\section{Figures}

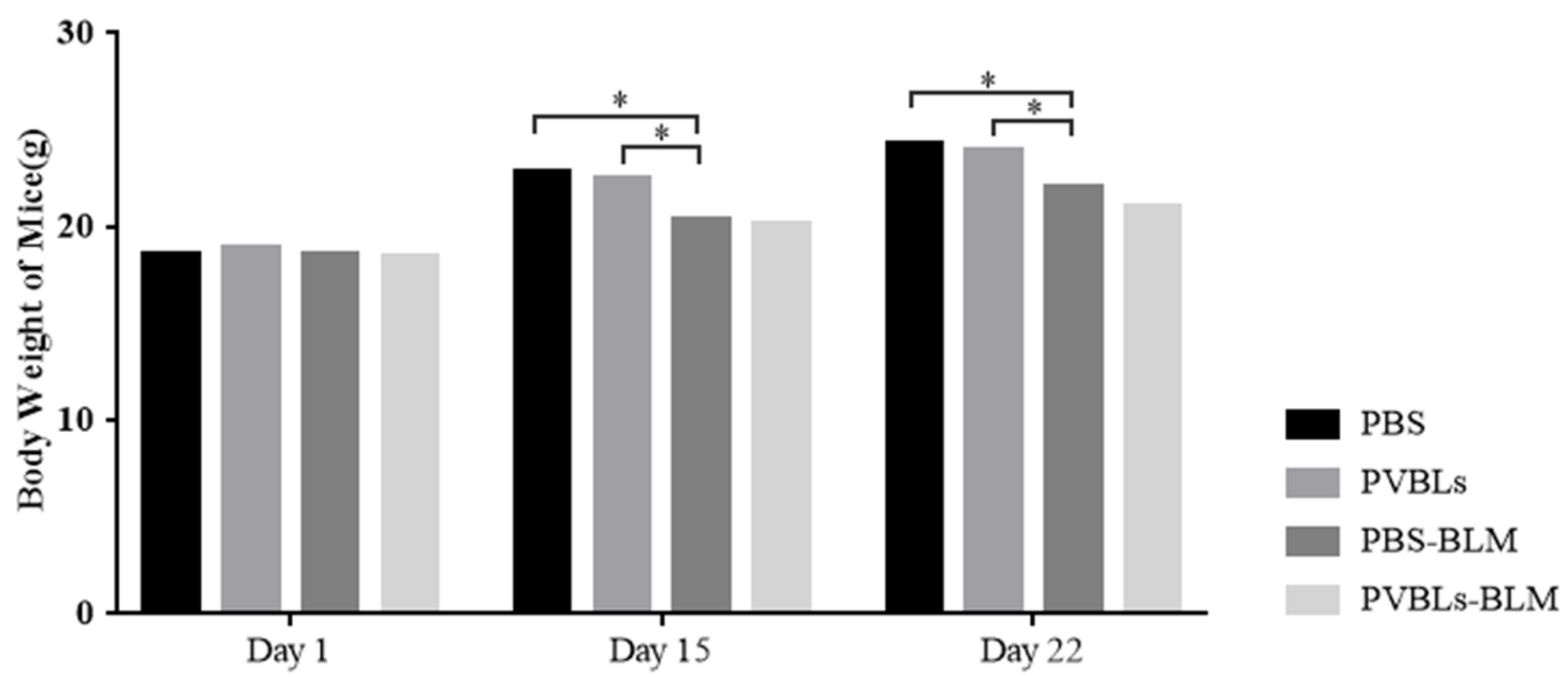

\section{Figure 1}

The body-weight difference between the animals with Bleomycin infusion and the controls reached statistical significance 7 days later after intra-tracheal infusion, and the difference maintained until the day of sacrifice $\left({ }^{*} P<0.05\right)$. 


\section{Figure 2}

Exposure to aerosol of PVBLs or PBS then intra-tracheal instillation of NS does not induce any discernible morphological abnormalities in pulmonary structural and alveolar septa (panel a and b). Intra-tracheal instillation of BLM causes a diffuse lung damage and a large scale of alveolar septa thickening (panel c). Repeat PVBLs pre-exposures alleviate the development of pulmonary fibrosis (panel d) (H\&E stain, $\times 40)$. $\mathrm{PBS}=$ phosphate buffer solution; PVBLs = polyvalent bacterial lysates; BLM = Bleomycin

\section{Supplementary Files}

This is a list of supplementary files associated with this preprint. Click to download.

- SupplementMaterial.pdf 